\title{
Importance of understanding laboratory strength and modulus testing data for deep mining in hard brittle rocks
}

\author{
RP Bewick Golder Associates Ltd., Canada \\ A Ouellet Golder Associates Ltd., Canada \\ S Otto Golder Associates Inc., USA \\ D Gaudreau Golder Associates Pty Ltd, Australia
}

\begin{abstract}
One common aspect of deep mining is the massive rock mass conditions leading to a failure process where new fractures are created through the rock. Therefore, the three dominate rock mass characteristics required for deep mining deposits are the strength, elastic properties, and pre-mining stress state. This paper focuses on characterising the strength parameters and elastic properties of rocks for deep mining purposes. Too often, strength testing data does not receive proper attention. Details are provided on the specification of confining pressures for both low (excavation skin) and high (squat pillars) confinement design specific challenges, the filtering of data to assess Hoek-Brown intact rock strength envelopes, and the interpretation of testing results.

Laboratory testing data from a deep mining deposit is presented to show appropriate filtering for the determination of strength by failure type. Next the importance of understanding the elastic properties is discussed and it is shown how different relative magnitudes in elastic moduli and lithologic unit geometry impact stress and strain changes between rock units. This understanding assists engineers in determining the modulus differences leading to potential stress but, more importantly, strain gradients in the rock mass that have the potential for the generation of seismicity and rockbursts.
\end{abstract}

Keywords: material parameters, modulus, compressive strength, brittle rock

\section{Introduction}

Rock masses in many deep or high stress mines are essentially massive or sufficiently not jointed such that failure process must involve the creation of new fractures through intact rock. Also, the rocks are often hard and brittle. Since these rock masses are not sufficiently jointed to allow for block rotation, rock mass strength cannot be estimated using the geological strength index (GSI) (Hoek et al. 1995), combined with the Hoek-Brown (HB) failure criterion (Hoek \& Brown 1980a; Hoek 1983). This is because the GSI-HB approach assumes that failure of the rock mass is through the rotation of well-defined rock blocks that are present at the excavation design scale of interest. Therefore, for deep mining, focus must be placed on understanding three main laboratory defined intact rock peak strength components: (1) tensile strength; (2) uniaxial compressive strength (UCS); and (3) confined strength using triaxial tests. Having these strength components well defined improves the ability to forecast the depth and shape of rock mass damage zones as well as their change over time due to mining induced stress changes.

While the peak strength components help to forecast damage zones, well defined elastic properties (i.e. Young's modulus and Poisson's ratio) help to assess stress and strain contrasts in the rock mass. Conventionally, laboratory determined elastic properties would be used to assess the rock mass deformation modulus using such approaches as proposed by Hoek and Diederichs (2006) where the GSI is used to estimate the field scale rock mass modulus; $E_{r m}$. Unfortunately, for massive rock masses, this approach for scaling modulus cannot be used for the same reasons as stated in the previous paragraph (i.e. GSI is not applicable). Furthermore, the displacements are often speculative since the failure process in massive rocks involves the 
creation of new fractures, and typically continuum models are used to assess damage zone development (i.e. a tool that does not allow for discrete fracture development and bulking of fractured rock). Recently, methodologies to improve displacement forecasting in continuum models for brittle failing rock masses have been proposed (e.g. Walton 2014) but these methods are still not sufficiently developed or proven to be considered within current rock engineering state-of-practice. Therefore, the definition of well constrained elastic properties at the laboratory scale is most helpful to assess locations within rock masses where stresses may be concentrating and where strains may be stored (i.e. locations of differential strain).

\subsection{Strength envelopes and confinement dependent failure processes: laboratory versus field}

Rupture of massive (intact non-jointed) brittle rock is easiest envisaged at the laboratory scale considering cylindrical shaped specimens. As a result of the fracturing processes changing with increasing confining stress, the rupture mode of the specimens changes (Paterson 1958; Jaeger \& Cook 1976; Velde et al. 1993; Escartin et al. 1997), as summarised in Figure 1 for cylindrical marble specimens (after Paterson 1958). In uniaxial compression, the dominant fracturing process in the specimen is the creation of long tensile fractures parallel to the applied axial load, which result in rupture of the specimen by axial splitting. As the confining pressure is increased, growth of tensile fractures is inhibited (e.g. Hoek 1968) and short en échelon arrays of tensile fractures form with the overall effect of changing the specimen's rupture mode from axial splitting to shear localisation. Eventually the specimen failure process becomes ductile resulting in plastic flow, specimen barrelling, and specimen collapse. The change in mechanism can be seen in the failure mode of the specimen and the change from brittle to ductile can be constrained using Mogi's line (Mogi 1966) and plotting the data in a $p^{\prime}-q$ diagram (where $p^{\prime}$ is the equivalent stress and $q$ the axial-deviator stress; equations shown in Figure 2(b), Schofield and Wroth (1968); Bewick and Kaiser (2014)), which shows when specimen collapse begins to occur, as shown in Figure 2 for Paterson's marble (Paterson 1958).

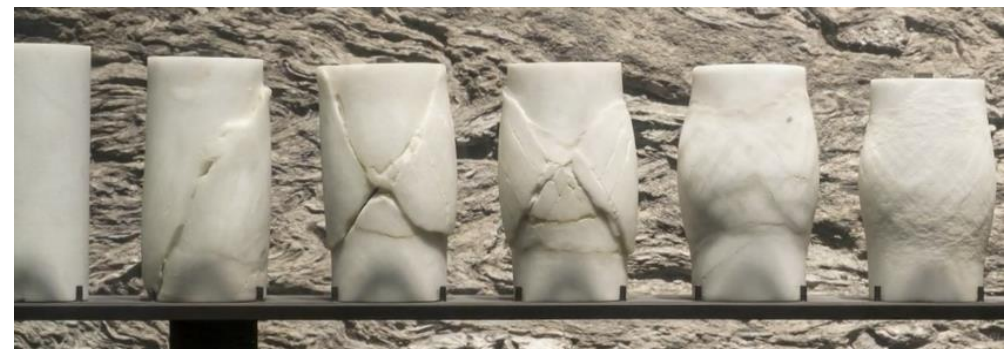

Figure 1 Example failure process change in Carrera marble (Paterson 1958). From axial splitting (left) to shear (centre) and to plastic flow (right)
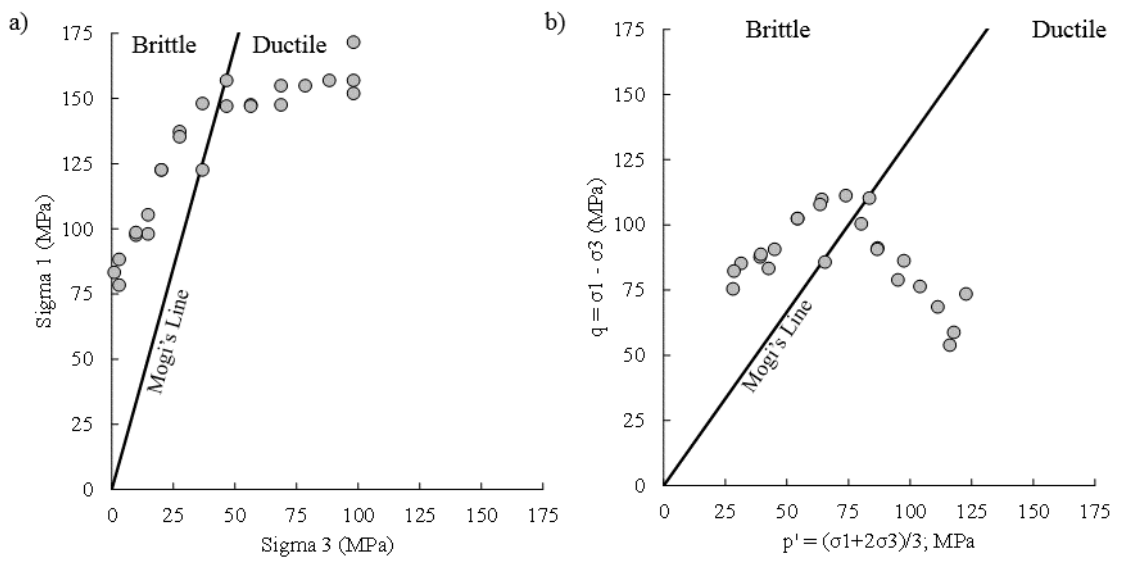

Figure 2 Data from Paterson (1958). Figure adapted from Bewick and Kaiser (2014) for Carrera marble showing the change in failure process from axial splitting to shear and the plastic flow (barrelling) after the brittle ductile transition (i.e. Mogi's line): (a) plotted in principal stress space; and, (b) plotted in a $\mathrm{p}^{\prime}$-q diagram 
At the field scale, the same failure process change can be seen as observed in the laboratory. At low confining pressures (such as near excavation boundaries), spalling occurs (i.e. analogous to axial splitting in the laboratory). At high confining pressures (such as in squat pillar cores), shear rupture occurs (i.e. analogous to shear localisation in the laboratory), (Bewick 2013). While failure process/modes are comparable, peak strength in the laboratory and in the field differ. At low confining stresses, spalling strength in the field occurs at 0.33 to 0.5 times the UCS of that determined in the laboratory. The field spalling strength has been found to be comparable to the crack initiation $(\mathrm{Cl})$ threshold in the laboratory with a slope considering the $\mathrm{HB}$ criterion of $m_{i}=0$ (Martin 1993; Castro et al. 1997; Diederichs 1999). At higher confining pressures, the field peak strength is typically found to be around a factor of 0.8 lower (i.e. $20 \%$ reduction of the HB strength envelope). This lowering at high confining pressure is found to be related to the crack damage (CD) threshold, which is the true material property strength of the rock (Diederichs 1999; Diederichs et al. 2010). Strength above $C D$ in the laboratory occurs due to testing machine stiffness, loading rate, and specimen geometry; among other factors. The spalling to shear rupture transition has been found to be bound by a spalling limit that ranges from $\sigma_{1} / \sigma_{3}=10$ to 20 (Kaiser et al. 2000).

Due to the change in failure process and, thus, ultimate failure mechanism in a rock mass with increasing confining pressure, the field strength envelope for brittle failing rocks is tri-linear (Kaiser et al. 2000; Kaiser \& Kim 2014). This envelope is shown in comparison to a hypothetical peak strength envelope in Figure 3. Therefore, the peak field strength envelope for hard brittle rocks can be determined from laboratory testing.

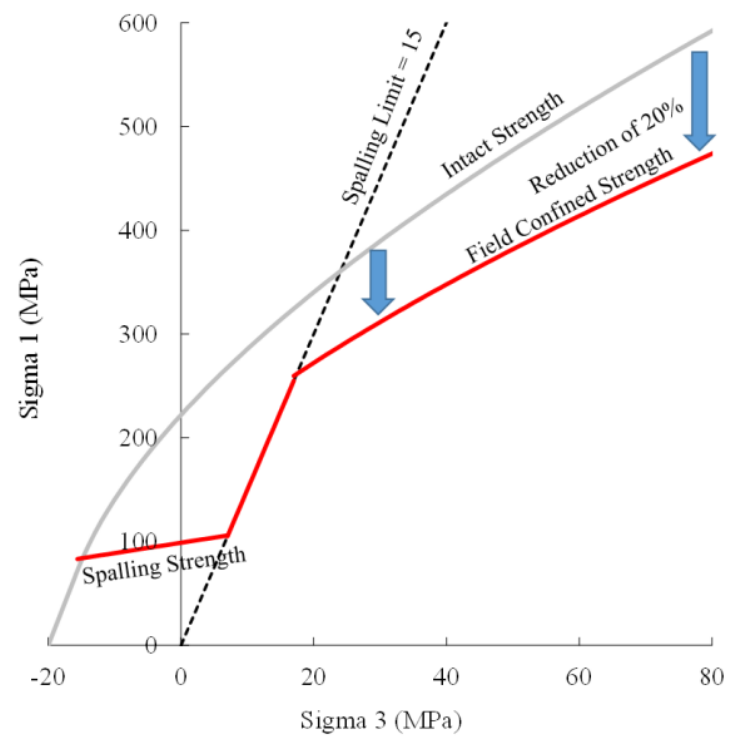

Figure 3 Tri-linear failure envelope relative to a $\mathrm{HB}$ intact strength envelope. For this example the spalling strength is 0.45 UCS and the spalling limit is $\sigma_{1} / \sigma_{3}=15$

For laboratory testing data to be used for field strength assessments, the data must be reliable and of good quality. All too often is laboratory data used blindly resulting in meaningless interpretations as shown in Figure 4, which shows a triaxial testing data set that has not been recorded or interpreted properly resulting in a poorly understood strength and range. In the next section, a set of laboratory testing data is used as an example to show appropriate data processing and interpretation. 

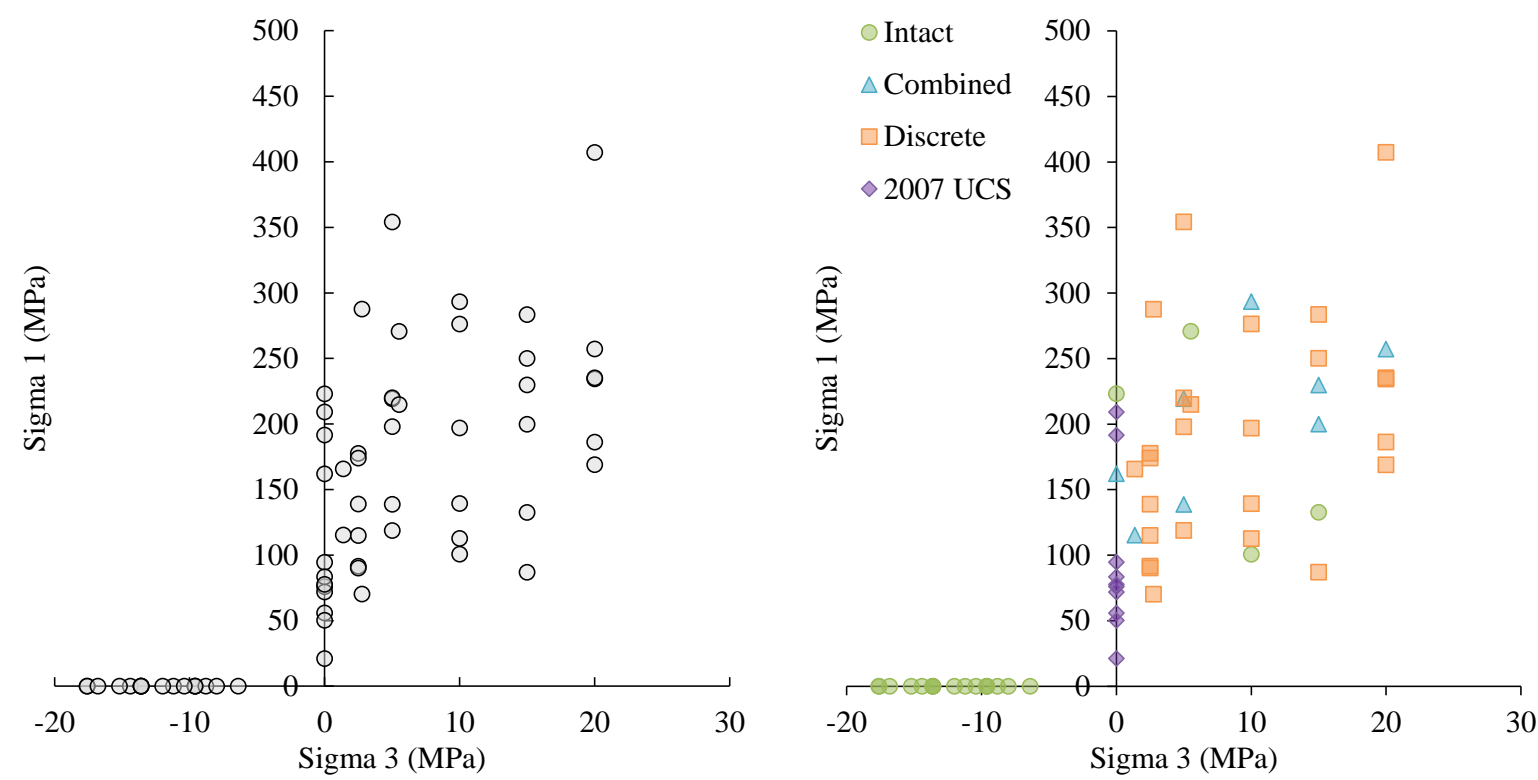

Figure 4 Example set of laboratory data where the data set was not properly processed. Limited understanding can be obtained from this set of laboratory testing data unless the reasons for the data scatter are determined, these are due to failure type variability (as shown on the right). Testing dataset from a meta-sedimentary rock unit (Golder 2016)

\section{$2 \quad$ Testing and interpretation methodology}

Laboratory testing should be completed to determine the tensile strength, UCS, and triaxial compressive strength (TCS) of laboratory scale specimens. Thus, focus should be placed on determining a reliable HB envelope for intact rock by observing the following criteria (Hoek \& Brown 1980a, 1980b):

- Data should be normalised to the diameter of a $50 \mathrm{~mm}$ specimen.

- Data should be sorted to remove invalid tests and tests that do not conform to a length to diameter ratio of 2.0 to 2.5 (the authors typically removed tests with a length to diameter $\leq 1.8$ ).

- Data should be filtered for axial splitting, shear-axial (or mixed mode), and shear failure modes to assess the spalling limit.

- Data should be filtered and processed separately for failure types by intact, combined, and discrete breaks as per Bewick et al. (2015). These failure types represent different failure types in the rock mass and should not be processed together (i.e. these are apples and oranges data sets). The significance of these tests are as follows:

- Intact - these tests can be used to establish a reliable intact rock strength.

- Combined - these test can be used to establish an estimated in situ rock block strength.

- Discrete - these tests can be used to establish the strength of bedding, veins, foliation etc.

- Data should only be fit in the brittle failure zone defined by Mogi (1966), i.e. to the left of Mogi's line. This is typically not an issue for rocks with UCS $>25 \mathrm{MPa}$.

- A minimum of five equally spaced triaxial data points covering a confining pressure range from 0 to $0.5 \cdot \sigma_{\text {ci }}$ Ideally, six data points should be used with three to the left and three to the right of a spalling limit of $\sigma_{1} / \sigma_{3}=15$ (Kaiser et al. 2015).

- HB envelope fit using tensile test data if available and without, for comparison. For instance, Hoek and Brown's original dataset for triaxial testing did not fit through the tensile strength (Hoek \& Brown 1980a). 
- If Brazilian indirect tensile testing data is what is available, these tests should be reduced by the factors $0.7,0.8$, and 0.9 for sedimentary, igneous, and metamorphic rocks, respectively (Perras \& Diederichs 2014).

As well as the $\mathrm{Cl}$ and $\mathrm{CD}$, thresholds should be determined to directly assess the field strengths at low and high confining pressures. If these values are not determined, then the field strength should be assumed to be:

- Under low confinement (left of the spalling limit): $\sigma_{\mathrm{rm}}=0.45 \cdot \mathrm{UCS}$ (or a range between 0.33 and 0.5 ), $m=0, s=1$.

- Under high confinement (right of the spalling limit): $0.8 \times \mathrm{HB}$ confined strength envelope.

- Spalling limit of $\sigma_{1} / \sigma_{3}=15$ (between the range of $\sigma_{1} / \sigma_{3}=10$ to 20 ).

\subsection{Processing of an example data set}

This section uses a calcite veined limestone from a mine prone to stress induced failure as an example data set (Figure 5(a)) to show the processing and interpretation procedure. The laboratory testing assumed a UCS of $100 \mathrm{MPa}$ and, thus, testing was completed up to a confining pressure of $50 \mathrm{MPa}$. The data was normalised to a $50 \mathrm{~mm}$ specimen diameter, invalid tests and tests not conforming to the correct length to diameter ratio were removed, indirect tensile strength was reduced by a factor of 0.7 (as per the recommendations of Perras \& Diederichs 2014), and failure types were sorted so that they can be processed separately (Figure 5(b)) as per Bewick et al. (2015). Failure modes were classified as axial splitting, a mix of shear-axial splitting, and shear localisation.
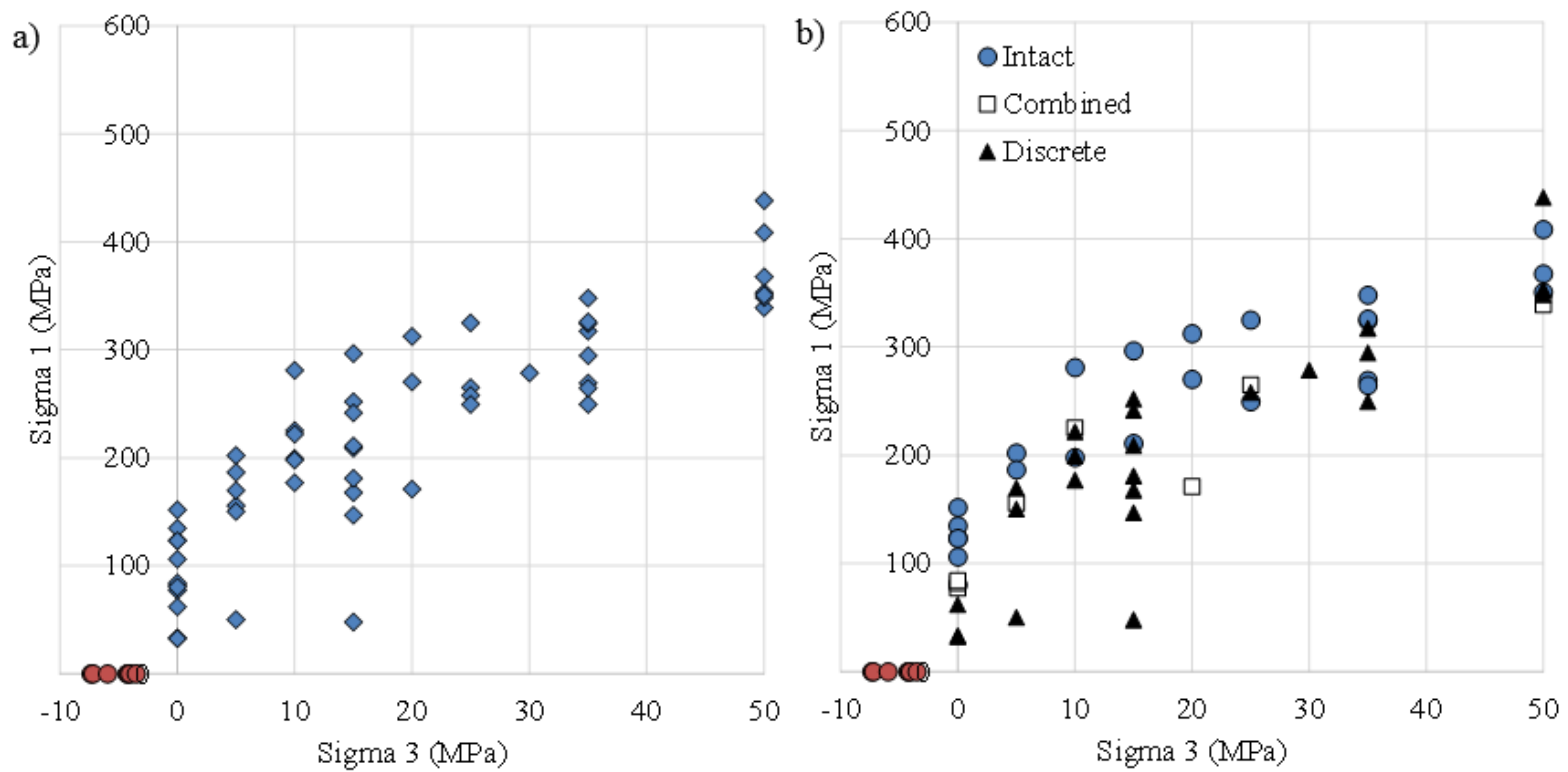

Figure 5 Example calcite veined limestone laboratory testing data set: (a) available data; and, (b) data sorted by failure type: intact; combined; and discrete as per Bewick et al. (2015). Tensile strength data points are also shown (red circles). Data from Golder (2015)

Next, the intact breaks were assessed to determine the HB fitting parameters using the procedure outlined by Hoek and Brown (1997). The spalling limit was assessed considering the failure modes. The fitting results are shown in Figure 6(a) and the determination of the spalling limit is shown in Figure 6(b). The spalling limit was limited to a range between $\sigma_{1} / \sigma_{3}=10$ to 20 (Kaiser et al. 2000) and was selected to intersect the middle of the shear-axial failure mode. In the case of this rock type, a spalling limit of $\sigma_{1} / \sigma_{3}=20$ was selected. 

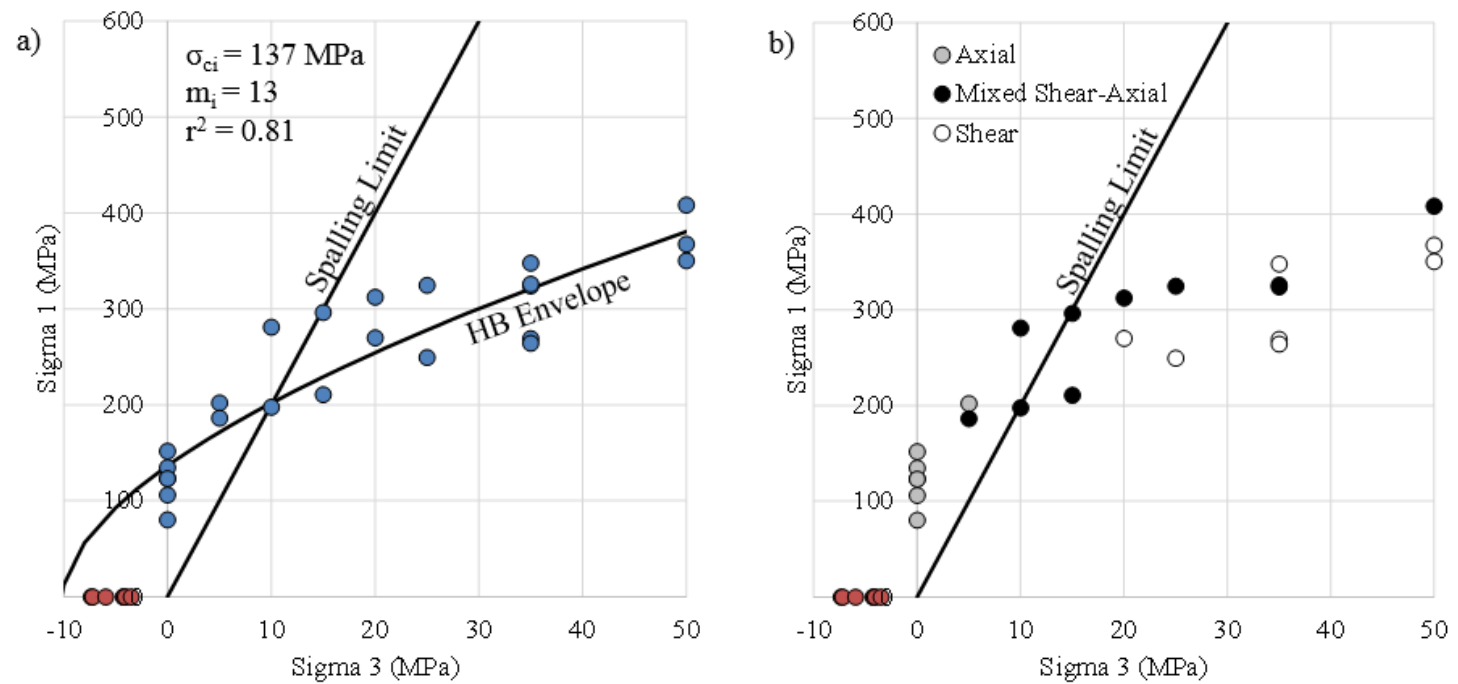

Figure 6 Intact failure type: (a) showing the HB envelope; and, (b) showing failure mode and the selection of the spalling limit. Tensile strength data points are also shown (red circles)

Some of the specimens failed as a combination of failure through intact rock and failure along pre-existing discontinuities (in this case, veins of calcite). Since combined failures have a high strength variability (Bewick et al. 2015) a large specimen database is needed to interpret the strength of this failure type. There are only a few data points for this rock type, and while a fit is provided to the data in Figure 7 , it is not considered fully reliable. Additional testing data would be required to better establish the strength and variability of the defected rock. For combined failure type, the terms $\sigma_{d}$ and $m_{d}$ are used (Kaiser et al. 2015) as equivalents for $\sigma_{c i}$ and $m_{i}$. The terminology is changed because the HB parameters are for intact rock breaks.

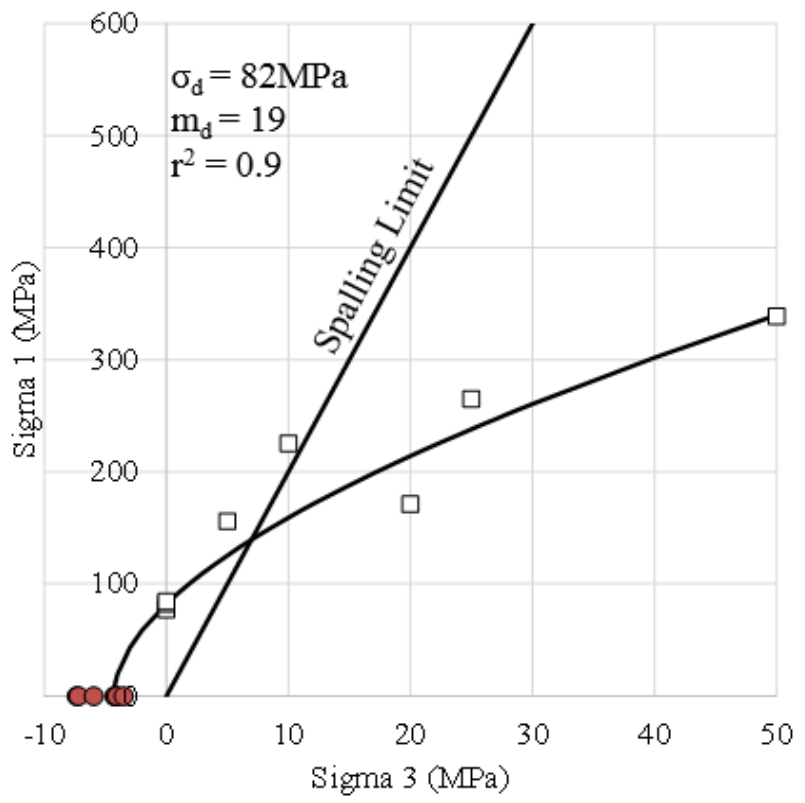

Figure 7 Combined failure type HB fit showing a spalling limit of 20. Tensile strength data points are also shown (red circles)

\subsubsection{Strength envelope for discrete breaks}

For the specimens that failed along discrete discontinuities, the strength of the healed discontinuity can be obtained. The challenge with discrete breaks is that, unless the discontinuity is oriented at an angle of $45^{\circ} \pm \phi / 2$ to the specimen axis, the data cannot be plotted or interpreted in principal stress space. For example, data from failure along three discrete discontinuities is plotted in the principal stress space in 
Figures $8(a)$ and $8(b)$, only the point from a critically oriented discontinuity represents the strength in principal stress space (blue square in Figure $8(b)$ ). The other data points, are neither representative of the discontinuity strength, nor of the rock strength. The scatter observed in discrete break data is largely a result of the varying discrete discontinuity orientation.
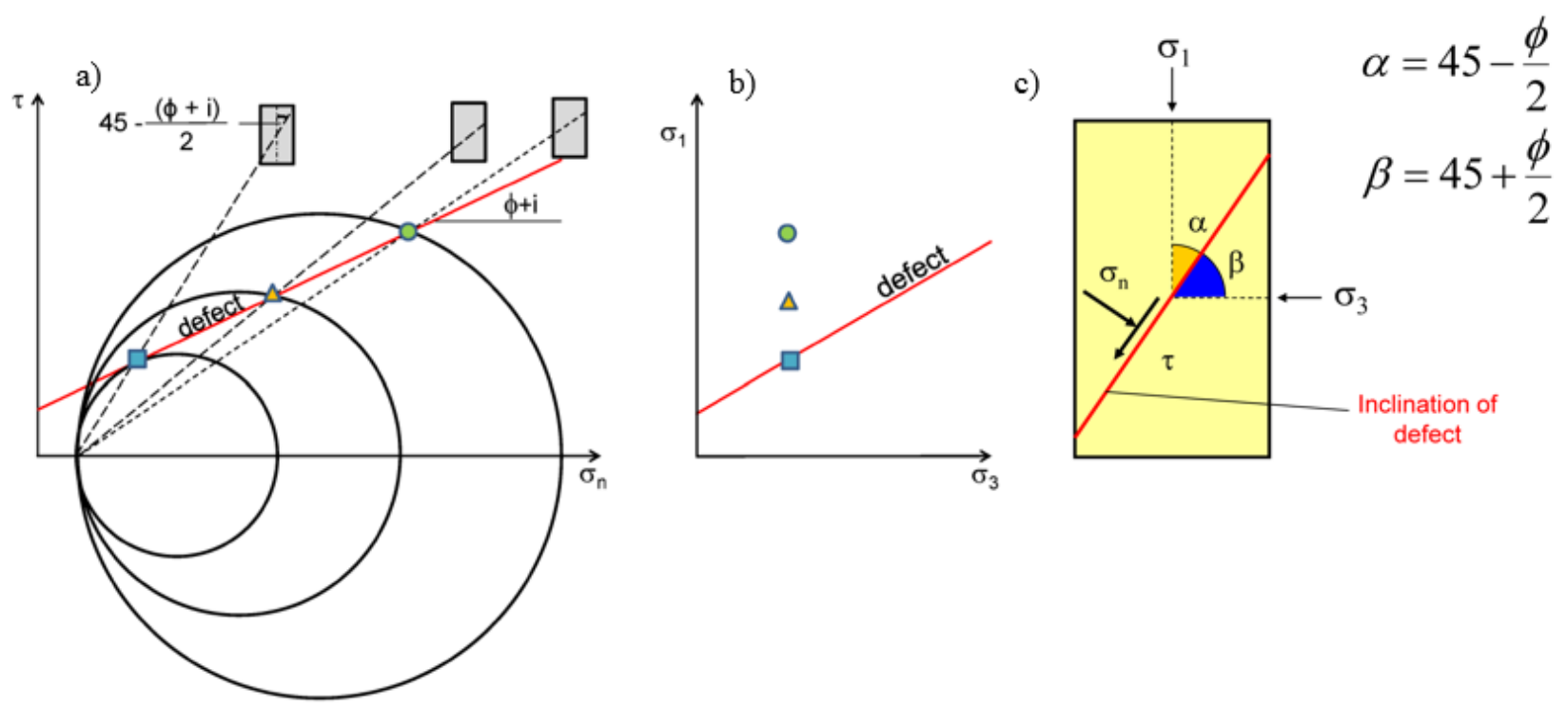

Figure 8 The reason why discrete failures cannot be processed in principal stress space: (a) normal stress and shear stress along a pre-existing discontinuity failure surface for a single confining pressure; (b) location of the data points in principal stress space (from Kaiser et al. 2015); and, (c) definition of failure angles alpha and beta

Discrete breaks along pre-existing discontinuities are required to be processed by converting the principal stress data into shear and normal stress along the failure plane. For this the orientation of the failure plane is needed. The shear stress acting on the discontinuity is:

$$
\tau=\frac{1}{2}\left(\sigma_{1}-\sigma_{3}\right) \sin (2 \beta)
$$

The normal stress is given by:

$$
\sigma_{n}=\frac{1}{2}\left(\sigma_{1}+\sigma_{3}\right)+\frac{1}{2}\left(\sigma_{1}-\sigma_{3}\right) \cos (2 \beta)
$$

where:

$\sigma_{1}$ and $\sigma_{3}$ are the maximum and minimum principal stresses at failure.

$\beta$ is the inclination of the discontinuity with respect to horizontal (Figure 8(c)).

The discrete break data for the presented data set is shown in Coulomb stress space in Figure 9(a) and transformed into principal stress space in Figure 9(b) using Equation (3).

$$
\sigma_{1}=\frac{2 c^{\prime} \cos \phi+\sigma_{3}(1+\sin \phi)}{1-\sin \phi}
$$

where:

$c^{\prime}$ is apparent cohesion and $\phi$ is friction angle.

$\phi$ can be replaced by $\phi+i$ (friction plus dilation angle).

Because there is limited shear displacement in trixial tests on rock specimens, the shear strength of the failure plane should be refered to as a friction plus dilation angle. The surface has not been sufficiently sheared to destroy the surface asparities that generate the dilation ' $i$ '. 

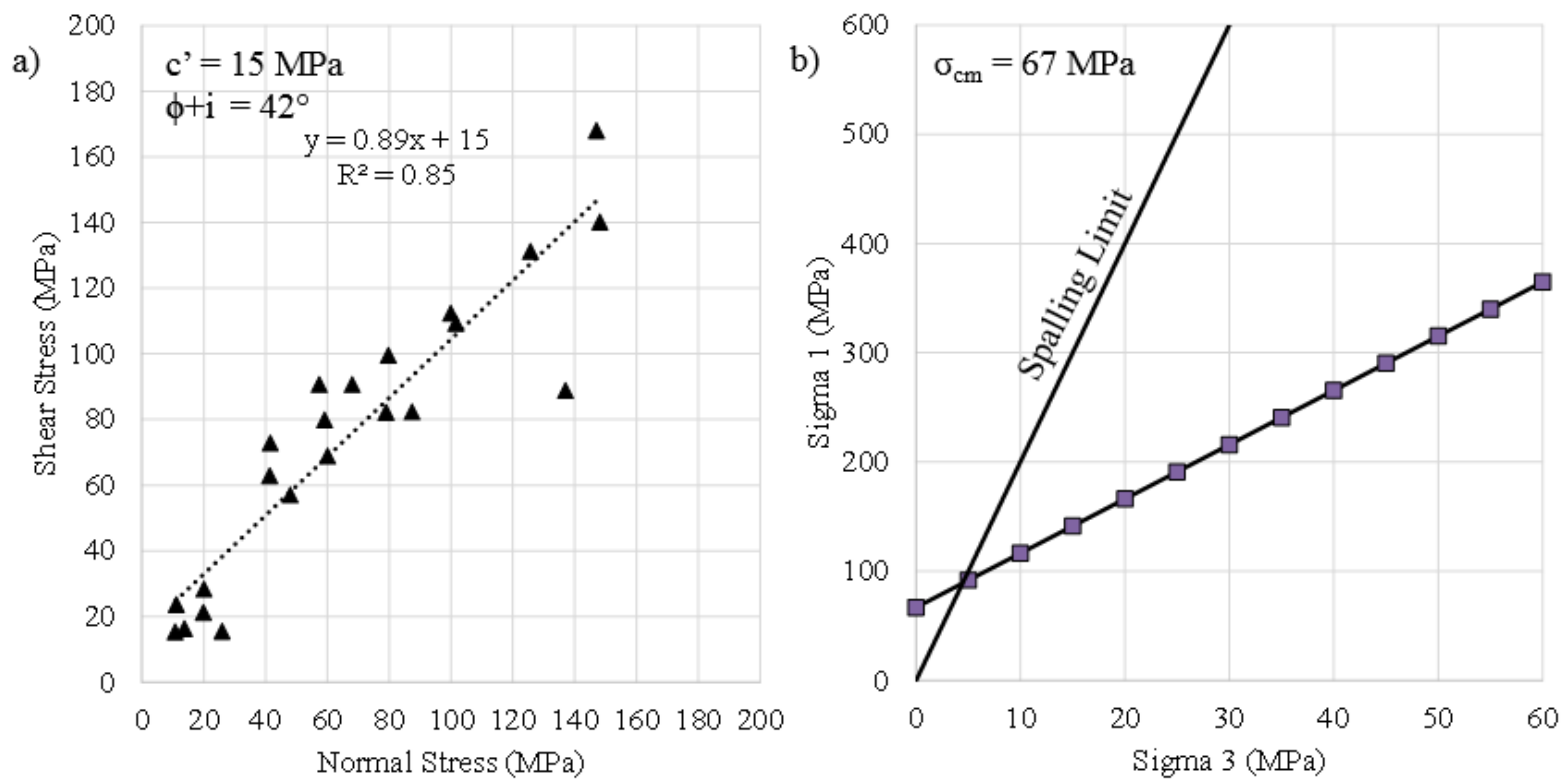

Figure 9 (a) Discrete failures (shown in Figure 5) assessed in Coulomb stress space showing fit to failure points ( $c^{\prime}$ is apparent cohesion, $\phi+i$ is the friction plus dilation angle). (b) Coulomb failure envelope fit transformed into principal stress space. The straight line in principal stress space represents the strength of the discrete vein breaks

\subsubsection{Strength envelope summary}

The strength envelopes for the failure types intact, combined, and discrete breaks are summarised in Figure 10. Each failure type data set has progressively decreasing strength from highest to lowest: intact, combined, and discrete. These envelopes are essentially representative of different components of rock mass strength.
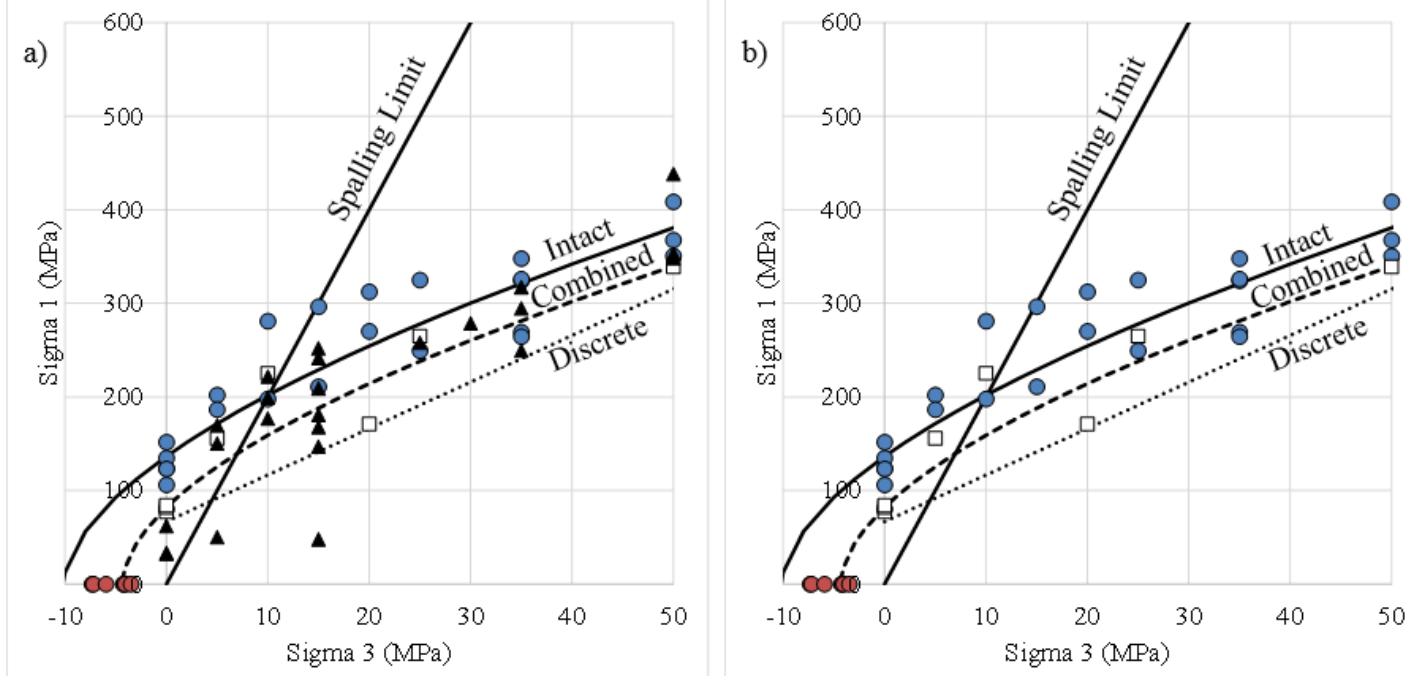

Figure 10 (a) Summary of failure envelopes for each failure type. (b) Discrete break failure points removed for clarity as well as inappropriate use of the discrete data. Circles intact breaks, squares combined breaks, and triangles discrete breaks

As outlined in Section 2.0, the field rock strength can be determined from the laboratory strength envelopes. Both the intact and combined break failure types are presented. In Figure 11(a), the intact break failure type data was used to develop the field tri-linear envelope, as shown in red while the combined break failure type data is shown in Figure 11(b), based on the procedure outlined in Section 2. 

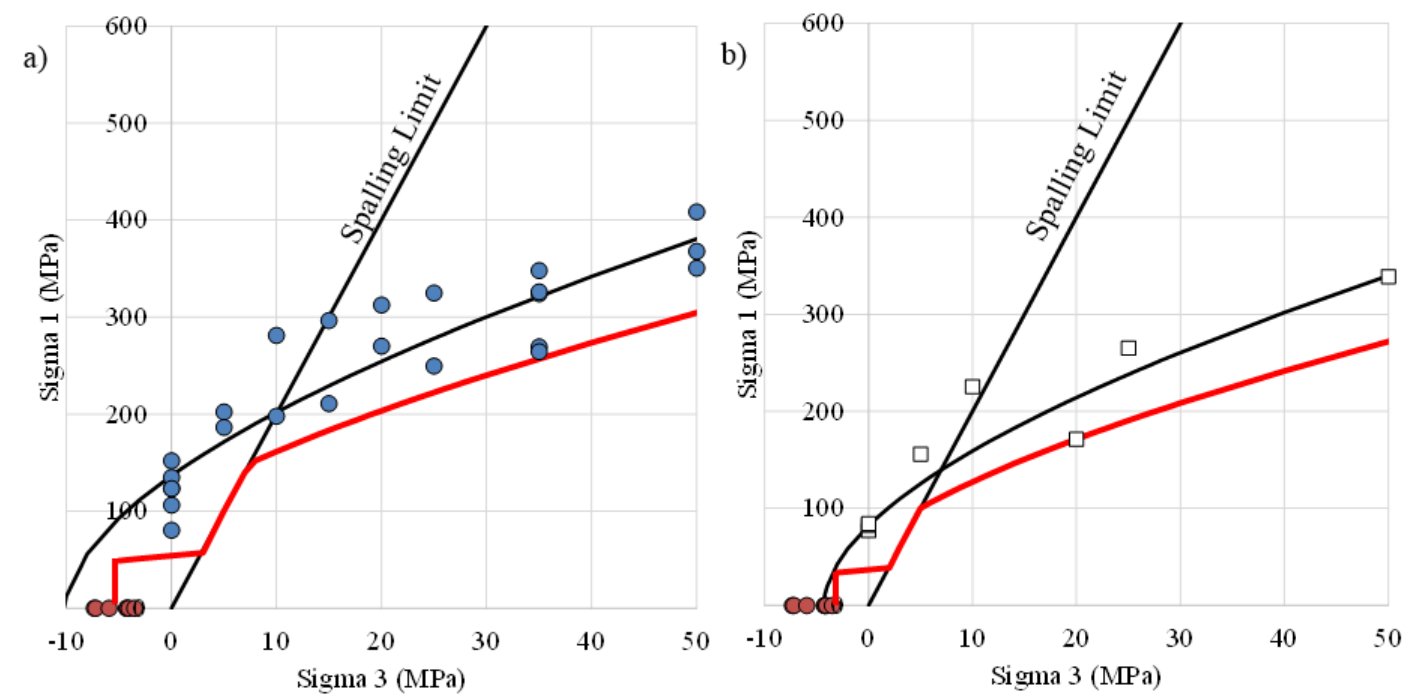

Figure 11 Example tri-linear strength envelopes determined from the laboratory strength testing data for (a) intact rock breaks and (b) combined breaks. Tension cut-off shown in (a) is the average of the tensile strength testing data and in (b) limited by the intercept with the HB envelope

\subsubsection{Impact of confining stress range on $H B$ parameters}

One of the constraints often over looked when fitting triaxial data with the HB criterion is the need to have confining pressure testing data up to $50 \%$ of the unconfined compressive strength of the material. The impact of confining stress range was investigated for the data set presented considering the intact failure type. Confining pressure was limited to $10,15,25,35$, and $50 \mathrm{MPa}$ and the $\mathrm{HB}$ fit parameters $\sigma_{c i}$ and $m_{i}$ for each confining pressure range are presented in Figure 12. As can be seen, the $\sigma_{c i}$ values are minimally impacted (ranging from 130 to $137 \mathrm{MPa}$ ) while the $m_{i}$ value is significantly impacted (ranging from 26 to 13). Clearly, if triaxial testing data is not available to the required $50 \%$ of the compressive strength of the material, extrapolation of the envelope past the available confining pressure should proceed with caution as the confined strengths could be overestimated due to the high $m_{i}$ values resulting when only limited confining pressures are tested.

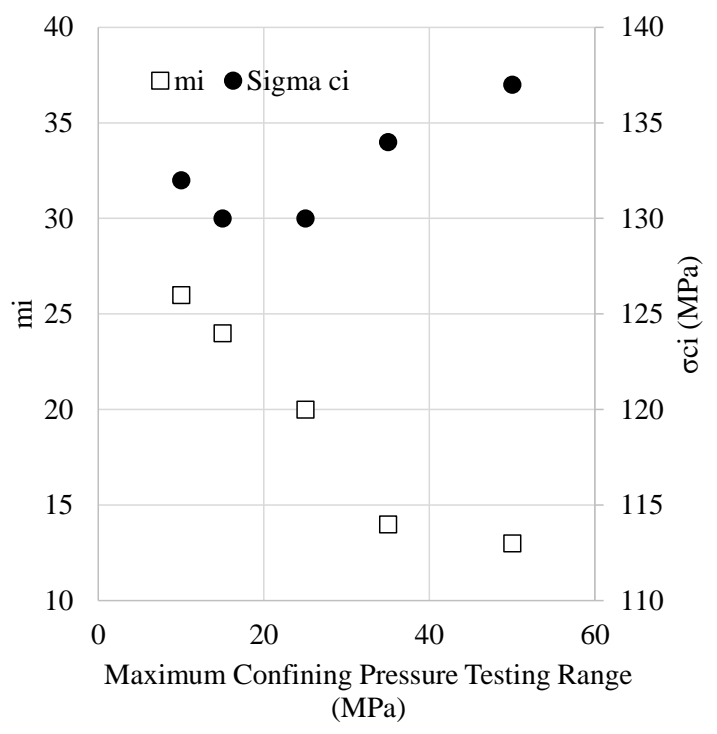

Figure 12 Change of $\mathrm{HB}$ fitting parameters $\sigma_{c i}$ and $m_{i}$ for testing data range (i.e. separate fits for data going to $10,15,25,35$, and $50 \mathrm{MPa}$ confining pressures)

The steepness of the failure envelope at low confining pressures is thought to be due to the progressive failure mode change from axial splitting to shear rupture as outlined in Bewick et al. (2011). Due to the 
mechanism change and the progressive flattening of the HB envelope at higher confining pressures, the tested confining pressures in hard brittle rocks should be evenly spaced on both sides of the spalling limit in addition to being tested to $0.5 \sigma_{\mathrm{ci}}$ as indicated by Hoek and Brown (1980a).

\section{Modulus contrasts}

Based on the previous sections, there is a clear benefit to understanding the strength of rock in the laboratory because these values can be directly used to determine the field strength in brittle failing rock masses. The other commonly collected data in the laboratory are elastic properties (i.e. Young's modulus, E and Poisson's ratio, v). While there is a relationship to assess field rock mass modulus using the GSI, GSI is not applicable in brittle failing rock masses. In brittle failing rock masses, the rock mass displacements are driven by the creation of new fractures and their subsequent opening due to straining of the failed or failing rock volume. While modulus from the laboratory cannot be used to assess a field scale rock mass modulus (at this time), the laboratory values can be used to assess stress and strain contrasts in the rock mass and, thus, areas more sensitive (due to higher stress) to failure, and more sensitive to energy release creating the conditions for rockbursting (due to strain differentials in the rock mass). While modulus is one component resulting in areas becoming more or less stressed, the geometry of the contrasting material also creates conditions for the focusing of stress, as shown in Figure 13.
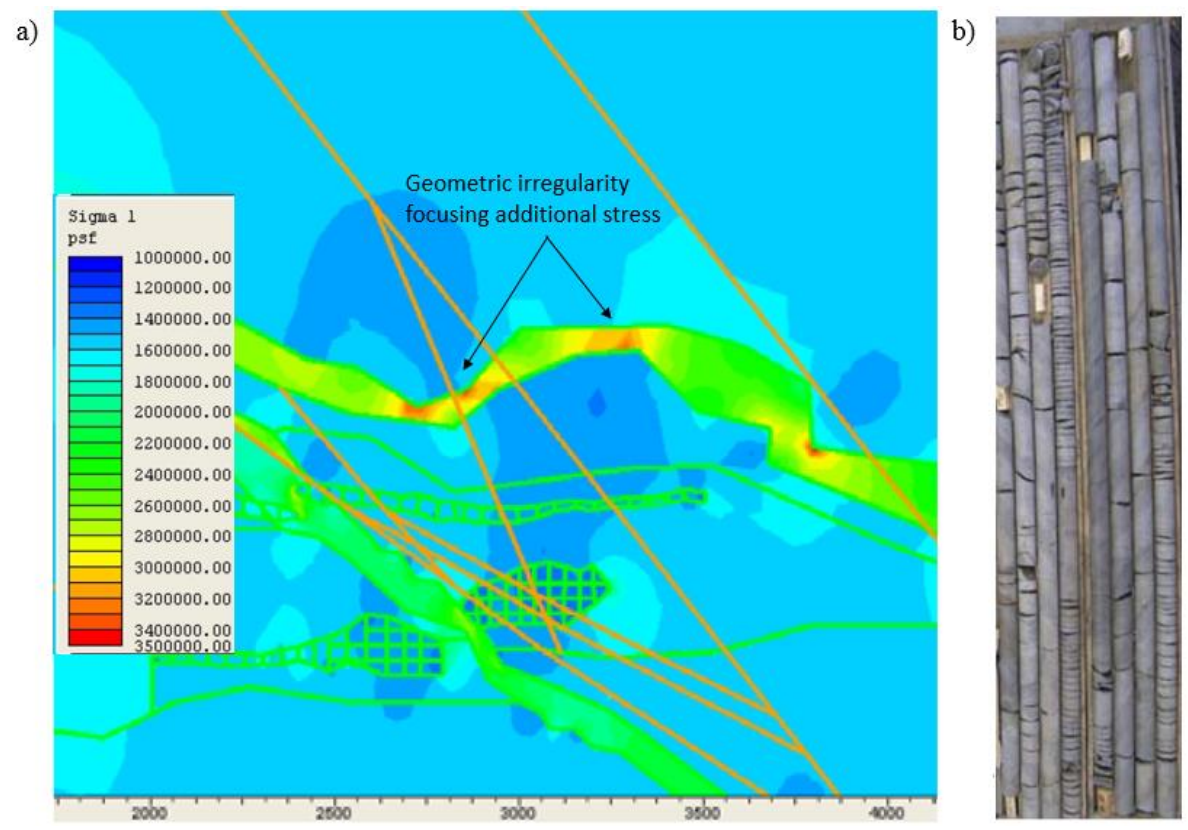

Figure 13 (a) Inclusion of a stiff ( $\mathrm{E} \sim 90 \mathrm{GPa}$ ) diabase dyke in a relatively softer host rock ( $\mathrm{E} \sim 60 \mathrm{GPa}$ ) showing how the dyke, though overall more stressed, is even more highly stressed in the geometric irregularities. (b) Core disking in dyke bends suggestive of high stress concentrations. Other locations did not have well developed core disking (modified from Bewick et al. 2009)

Recently, laboratory testing of a potential future deep mine (Golder 2016) suggested that the ore zone contained modulus values ranging from 90 to $250 \mathrm{GPa}$ (Figure 14) while the host rocks were consistently around $90 \mathrm{GPa}$ (Figure 14). The orebody in some locations was also geometrically complex. Due to the modulus contrasts between host rock and the ore zone, as well as the ore zones geometry (Figure 15), the impact of modulus contrast and geometry was assessed. For this purpose, and to show the relative influence of stiff inclusions (i.e. high modulus ore zone relative to the host rock) and softer inclusions (i.e. low modulus ore zone relative to the host rock), a sensitivity was completed for five ore zone modulus values of $150,125,100,75$, and $50 \mathrm{GPa}$ or $1.7,1.4,1.1,0.8$, and 0.6 times the host rock modulus of $90 \mathrm{GPa}$ assuming a depth below surface of $1,500 \mathrm{~m}$. Stresses of this future deep mine are characteristic of the Canadian Shield and have been estimated using the relationships proposed by Maloney et al. (2006) resulting in a major horizontal stress $\left(\sigma_{H}\right)$ of $61 \mathrm{MPa}$ acting east-west (relative to the ore zone in Figure 15) 
and a minor horizontal stress $\left(\sigma_{h}\right)$ of $41 \mathrm{MPa}$ acting north-south (relative to the ore zone in Figure 15$)$. The models were loaded using displacement boundaries. The displacements were increased until the far field in situ stress reached the desired magnitudes for the $1,500 \mathrm{~m}$ depth. The major principal stress $\left(\sigma_{1}\right)$, minor principal stress $\left(\sigma_{3}\right)$, and the major principal strain $\left(\varepsilon_{1}\right)$ were assessed for the five cases simulated and are summarised in Table 1 . The 150 and $50 \mathrm{GPa}$ model results are shown graphically in Figures 16 and 17 (only these are shown due to space considerations).

Table 1 Summary of ore zone modulus value on stress increase and strain differential (see Figure 15 for locations of offsets, straight sections, bends, and tip)

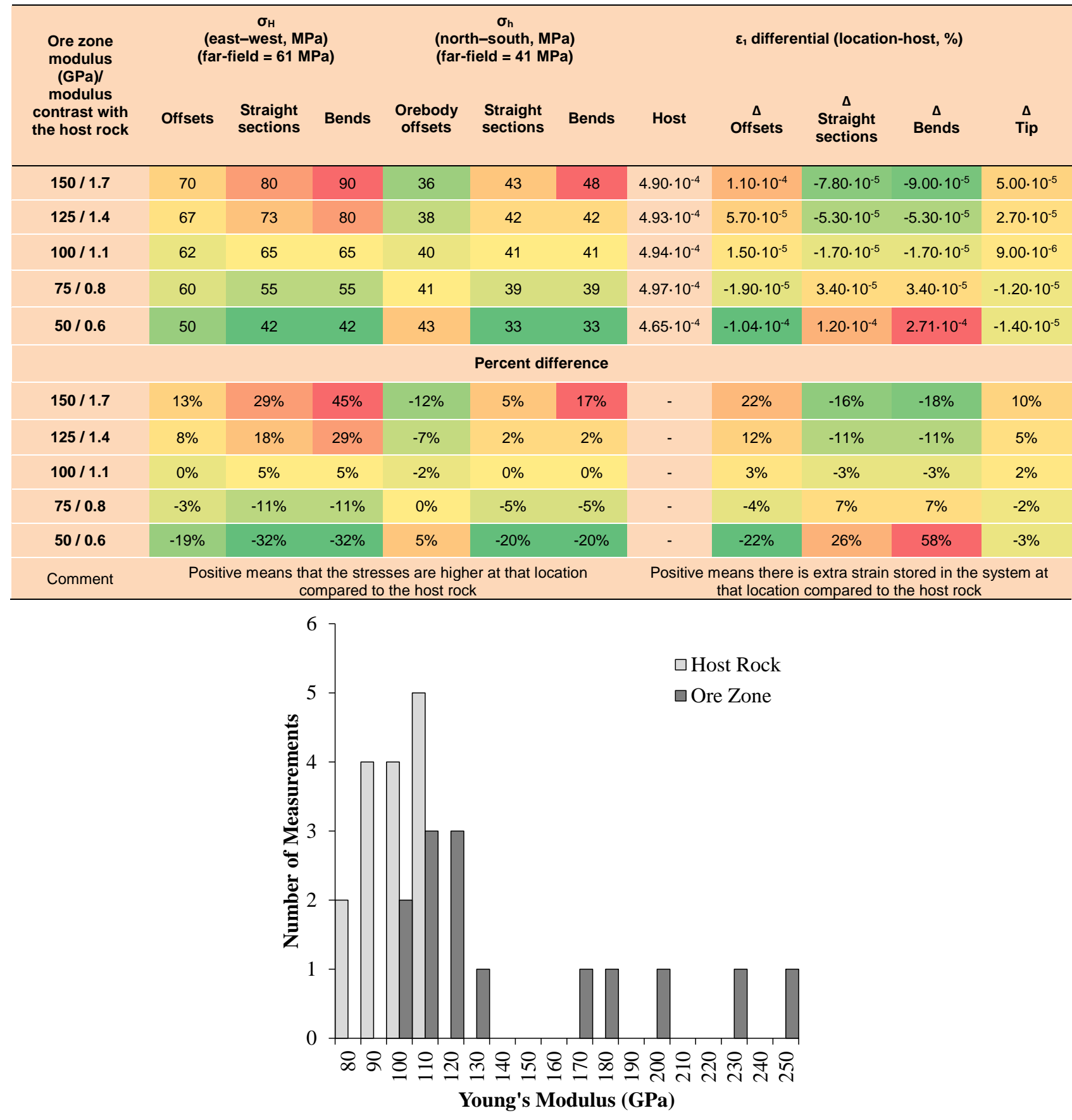

Figure 14 Histogram of Young's modulus for host rock and ore zone 


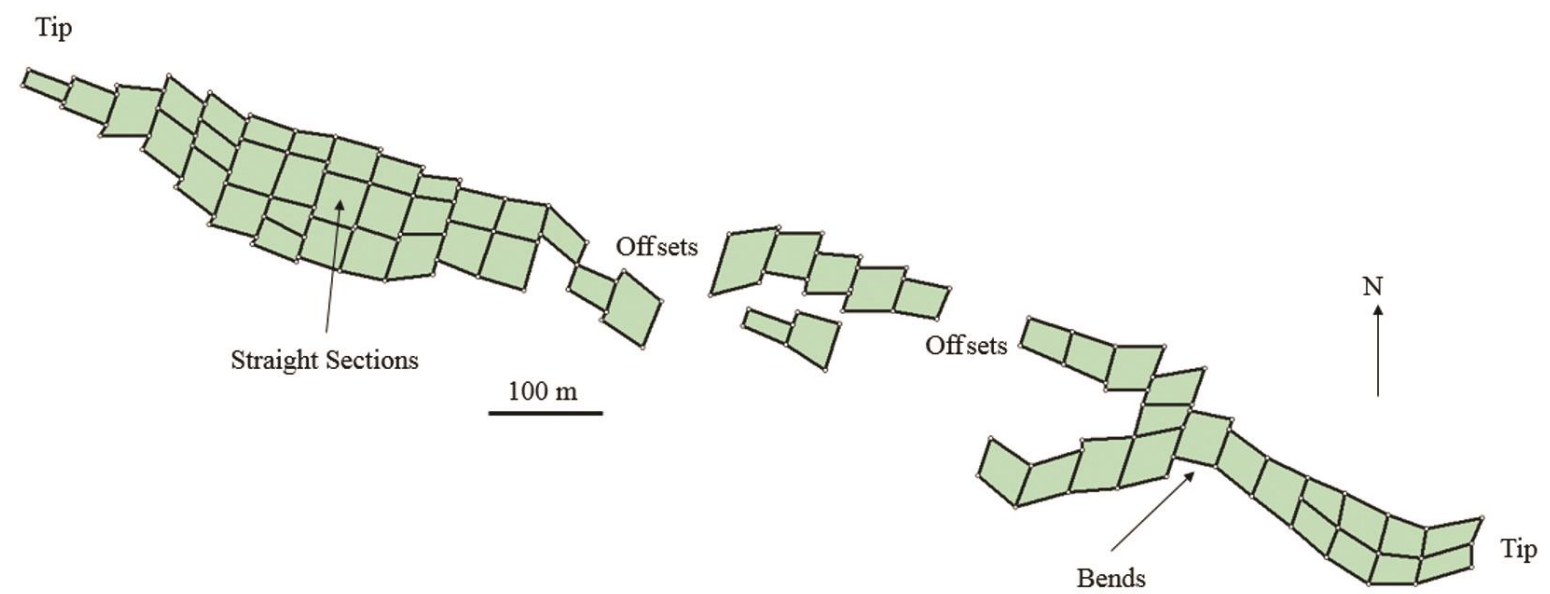

Figure 15 Example ore zone geometry in plan view showing locations of offsets, bends, straight sections, and tips

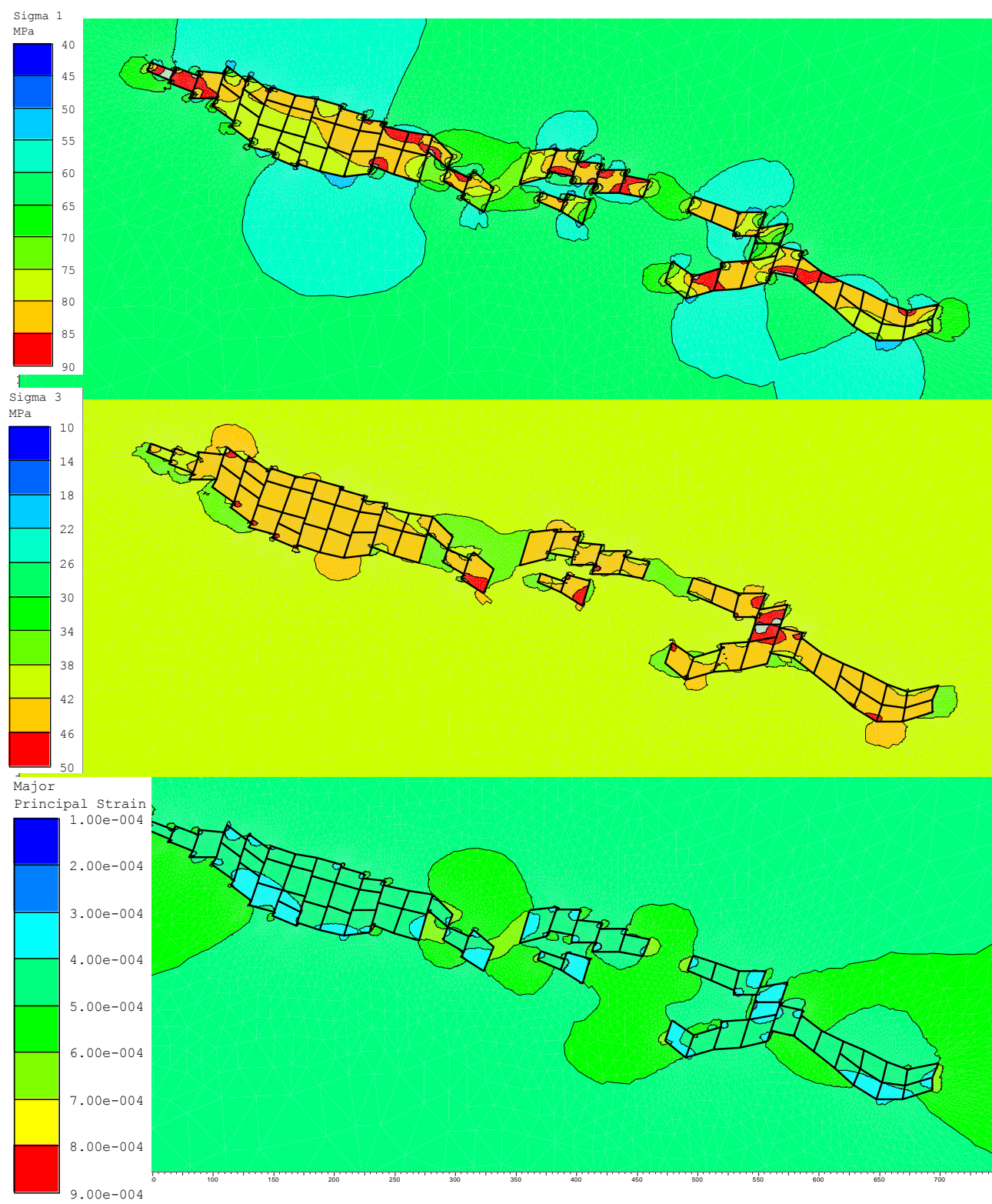

Figure 16 Ore zone modulus of $150 \mathrm{GPa}$ with host rock modulus of $90 \mathrm{GPa}$ : (top) Sigma 1; (middle) Sigma 3; and, (bottom) major principal strain 


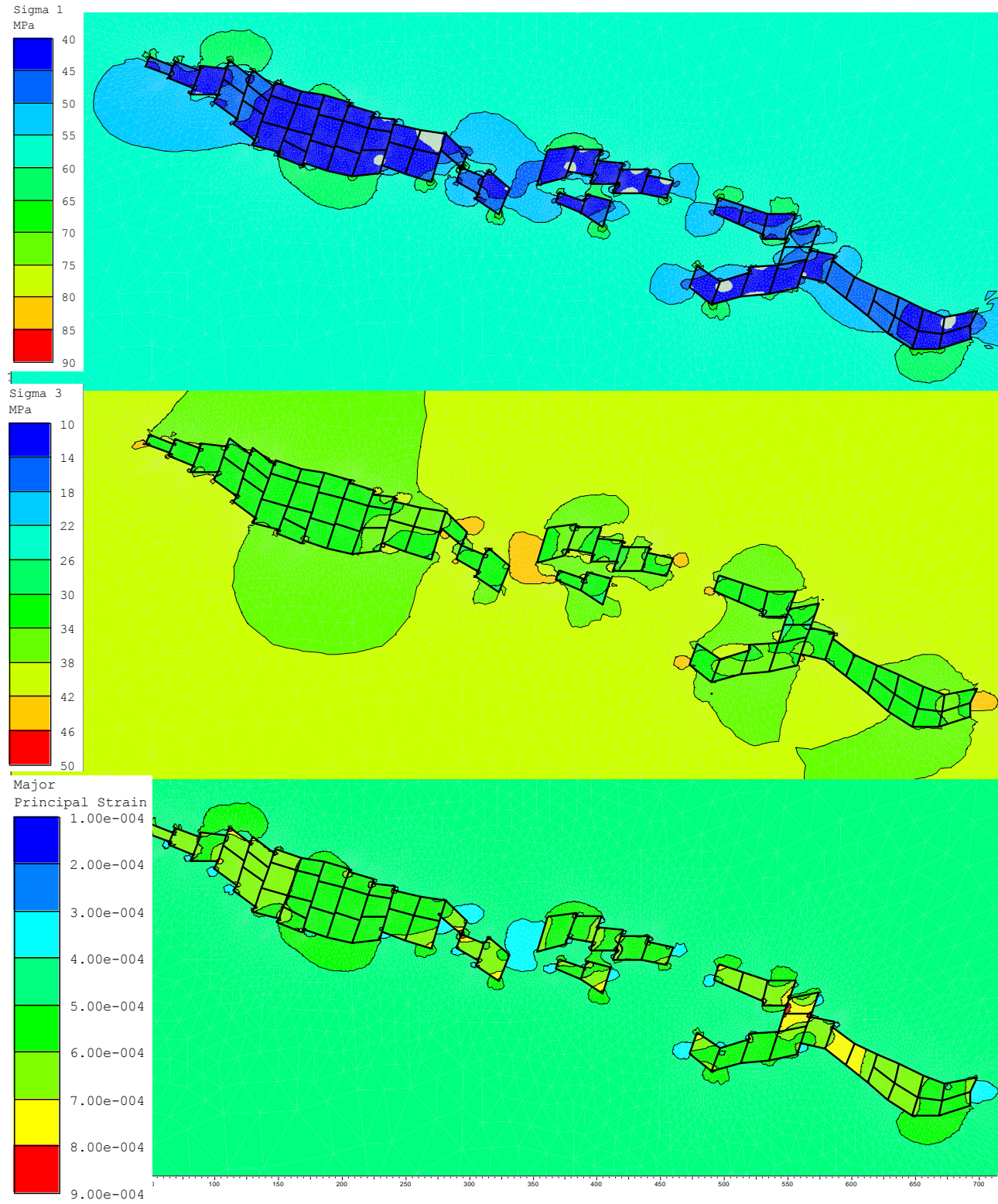

Figure 17 Ore zone modulus of $50 \mathrm{GPa}$ with host rock modulus of $90 \mathrm{GPa}$ : (top) Sigma 1; (middle) Sigma 3; and, (bottom) major principal strain

The results summarised in Table 1 and Figures 16-17 show that stresses can be increased up to $45 \%$ in locations of higher modulus and geometric irregularity. In addition, strains can be increased up to $22 \%$ around offsets of stiff inclusions. The results also suggest that when there is a modulus contrast of at least $30 \%$, there is the potential for higher stress concentrations and areas of stored strain energy. The significance of stored strain will be outlined in Section 4.

\section{Discussion}

The strength of the rock dictates when a failure process starts to occur, such as the spalling of near excavation boundary rock or the shear rupture of a pillar core. One of the predominant factors impacting the energy release potential (i.e. rockbursting potential) of the failure process is the stiffness of the loading system. The simplest analogue to loading system stiffness is that of a stiff and soft loading frame for the testing of rock core specimens as outlined by Salamon (1970). In a soft loading frame (relative to the rock being compressed), the frame strains disproportionately to the rock specimen during loading. These strains are elastic and stored in the loading frame. Once the specimen begins to fail, the stored strain is instantaneously 
transferred back into the specimen resulting in a violent explosive failure. When the loading frame is as stiff as or stiffer than the specimen being loaded, there is little to no stored strain energy in the loading frame. Thus, when the rock specimen begins to fail, assuming that the specimen itself cannot store excess energy (which some can), the failure of the specimen is gradual.

Loading system stiffness is not as simple as a concept to understand at the mine scale since the parameter depends on the (Crouch 1974; Aglawe 1999):

- Elastic properties of the rock mass.

- Mining geometry in the neighbourhood of the location undergoing a failure process.

- Effective moduli of the surrounding unmined portions of the orebody.

- Backfill material.

- Change in stiffness as surrounding segments of the orebody either are mined or become softer due to increased yielding.

- Shape and size of underground openings (excavation geometry).

- Stress ratio (loading).

- Shape and size of the damage zones surrounding individual excavations (yield geometry).

Strain differentials were presented in Section 3.0. These strain differentials represent volumes in the rock mass where excess strain energy is stored and essentially are pockets of low loading system stiffness (stored strain energy). While not all factors leading to increases in stored strain energy in the rock mass can be taken into account, simple modelling can be used if the modulus and geometry of the lithology units are understood to identify locations more prone to energy release during failure (e.g. areas more prone to rockbursting). Critical to this assessment, aside from quality data, is the use of displacement boundaries on numerical stress models. If displacement boundaries are not used, the materials in the model do not strain at different rates, thus, no higher and lower strained areas are generated. Other sources of data, such as core disking, can also be used to confirm areas of higher stress that could also highlight areas with stored strain energy. This can be seen in Figure 18 where a network of mapped faults has been incorporated into a numerical stress model and 'loaded' using displacement boundaries. The model results show areas of higher stress, which correlates quite well with core disking. The higher stress zones represent areas of lower strain and, thus, the fault has 'extra' strain stored in it creating the potential for increased fault slip rockbursting.

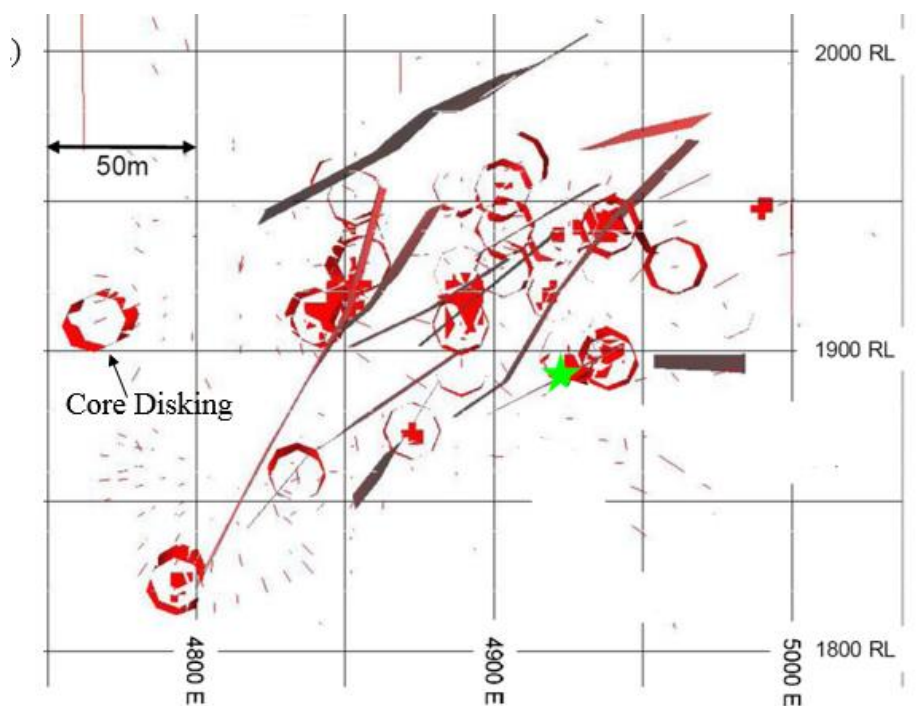

Figure 18 (a) Mapped fault locations and core disking. (b) Numerical stress model 'loaded' with

displacement boundaries showing locations of higher stress (green zones) which occur in the locations of core disking in (a). From Valley (2012)

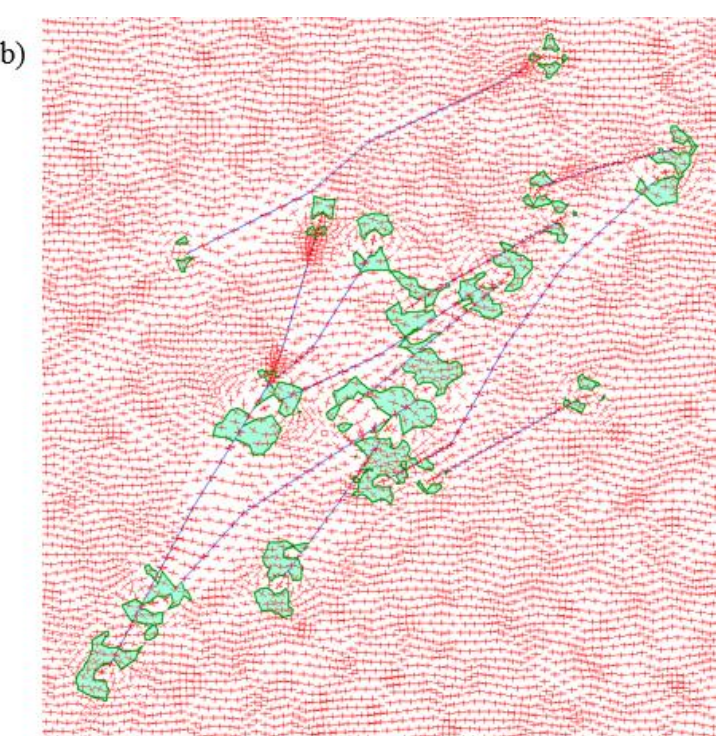




\section{Conclusion}

Proper interpretation of laboratory testing data is critical in hard brittle rocks prone to stress fracturing. Meaningless strength and modulus variability, mean values, and poor Hoek-Brown envelope fits are obtained when testing data is not properly processed. This may result in inappropriate rock engineering designs.

Laboratory strength data should be sorted by both failure mode (axial splitting, mixed splitting/hear, and shear rupture) and failure type (intact rock, combination of through intact rock and along healed discontinuities, and along discrete healed discontinuities). While failure modes may be processed together, failure types are independent strength parameters and should not be blended together.

Quality and well interpreted laboratory strength data can be used to directly assess the spalling limit, field spalling (low confinement), and shear rupture (high confinement) strengths.

Understanding modulus contrasts in the rock mass helps to understand rock volumes that have elevated stress magnitudes as well as strain gradients (i.e. volumes that are strained to higher amounts relative to their surrounding volume resulting in stored strain energy in the rock mass). These areas of higher stress are more sensitive to failure while the volumes of excess strain are more sensitive to rockbursting. Simple displacement controlled numerical stress models can be used to assess these locations in the rock mass if lithologic geometry (or fault geometry) and elastic properties are constrained.

\section{Acknowledgement}

The ideas presented in this paper are fortunate enough to have been discussed with Dr Peter Kaiser (Professor Emeritus) and Dr Florian Amann (ETH Zurich) over the last few years. Their thoughtfulness, discussions, making their time available, and insights are most greatly acknowledged.

\section{References}

Aglawe, J 1999, Unstable and Violent Failure around Underground Openings in Highly Stressed Ground, PhD thesis, Queen's University, Kingston.

Bewick, RP 2013, Shear Rupture of Massive Brittle Rock under Constant Normal Stress and Stiffness Boundary Conditions, PhD thesis, University of Toronto, Toronto.

Bewick, RP \& Kaiser, PK 2014, 'Discussion on “An Empirical Failure Criterion for Intact Rocks” by Peng et al. (2013)', Rock Mechanics and Rock Engineering, 47: 817. doi:10.1007/s00603-013-0514-4.

Bewick, RP, Kaiser, PK \& Valley, B 2011, 'Interpretation of triaxial testing data for estimation of the Hoek-Brown strength parameter $\mathrm{m}_{\mathrm{i}}^{\prime}$, Proceedings of the 45th US Rock Mechanics/Geomechanics Symposium, American Rock Mechanics Association, Alexandria.

Bewick, RP, Amann, F, Kaiser, PK \& Martin, CD 2015, 'Interpretation of UCS test results for engineering design', Proceedings of the 13th ISRM International Congress of Rock Mechanics, International Society for Rock Mechanics, Lisboa.

Bewick, RP, Valley, B, Runnalls, S, Whitney, J \& Krynicki, Y 2009, 'Global approach to managing deep mining hazards', in M Diederichs \& G Grasselli (eds), Proceedings of the 3rd CANUS Rock Mechanics Symposium, May, Toronto, paper 3994.

Castro, LAM, Grabinbsky, MW \& McCreath, DR 1997, 'Damage imitation through extension fracturing in a moderately jointed brittle rock mass', Proceedings of the 36th U.S. Rock Mechanics Symposium, 30 June-2 July, New York.

Crouch, S 1974, 'Analysis of rock bursts in cut and fill stopes', Journal of Scientific \& Industrial Research, vol. 256, pp. 298-303.

Diederichs, MS 1999, Instability of hard rock masses: the role of tensile damage and relaxation, PhD thesis, University of Waterloo, Waterloo.

Diederichs, MS, Carter, T \& Martin, DC 2010, 'Practical rock spalling prediction in tunnels', World Tunneling Congress, Vancouver.

Escartin, J, Hirth, G \& Evans, B 1997, 'Nondilatant brittle deformation of serpentinites: Implications for Mohr-Coulomb theory and the strength of faults', Journal of Geophysical Research, vol. 102, pp. 2897-2913.

Golder 2015, Laboratory testing completed for a veined limestone, Golder Associates Ltd.

Golder 2016, Laboratory testing completed at Golder's Rock Testing Laboratory for a Meta-Sedimentary rock unit, Golder Associates Ltd. Hoek, E 1983, 'Strength of jointed rock masses', Geotechnique, vol. 23, no. 3, pp. 187-223.

Hoek, E 1968, 'Brittle failure of rock', in KG Stagg \& OC Zienkiewicz (eds), Rock Mechanics in Engineering Practice, Wiley, London, pp. 99-124.

Hoek, E \& Brown, ET 1980a, Underground excavations in rock, Institution of Mining and Metallurgy, London.

Hoek, E \& Brown, ET 1980b, 'Empirical strength criterion for rock masses', Journal of Geotechnical and Geoenvironmental Engineering, American Society of Civil Engineers, vol. 106, no. GT9, pp. 1013-1035. 
Hoek, E \& Brown, ET 1997, 'Practical estimates of rock mass strength', International Journal of Rock Mechanics and Mining Sciences, vol. 34, no. 8, pp. 1165-1186.

Hoek, E \& Diederichs, MS 2006, 'Empirical estimation of rock mass modulus', International Journal of Rock Mechanics and Mining Sciences, vol. 43, pp. 203-215.

Hoek, E, Kaiser, PK \& Bawden, WF 1995, Rock support for underground excavations in hard rock, Balkema, pp. 215.

Jaeger, JC \& Cook, NGW 1976, Fundamentals of Rock Mechanics, 2nd edn, Chapman and Hall, London.

Kaiser, PK \& Kim, B-H 2014, 'Characterization of strength of intact brittle rock considering confinement-dependent failure processes', Rock Mechanics Rock Engineering. doi: 10.1007/s00603-014-0545-5.

Kaiser, PK, Amann, F \& Bewick, RP 2015, 'Overcoming challenges of rock mass characterization for underground construction in deep mines', Proceedings of the 13th ISRM International Congress of Rock Mechanics, International Society for Rock Mechanics, Lisboa.

Kaiser, PK, Diederichs, MS, Martin, CD, Sharp, J \& Steiner, W 2000, 'Underground works in hard rock tunneling and mining', Proceedings of the International Conference on Geotechnical and Geological Engineering, vol. 1, invited papers, Melbourne, pp. 841-926.

Maloney, S, Kaiser, PK \& Vorauer, A 2006, 'A re-assessment of in situ stresses in the Canadian Shield', Proceedings of the 41st US Symposium on Rock Mechanics - 50 years of Rock Mechanics - Landmarks and Future Challenges, Golden, Colorado.

Martin, CD 1993, Strength of massive granite around underground openings, PhD thesis, University of Manitoba, Manitoba.

Mogi, K 1966, 'Pressure dependence of rock strength and transition from brittle fracture to ductile flow', Bulletin of the Earthquake Research Institute, vol. 44, pp. 215-232.

Paterson, MS 1958, 'Experimental deformation and faulting in Wombeyan marble', Geological Society of America Bulletin, vol. 69, pp. 476-548.

Perras, MA \& Diederichs, MS 2014, 'A review of the tensile strength of rock: concepts and testing', Geotechnical and Geological Engineering, vol. 32, pp. 525-546.

Salamon, MDG 1970, 'Stability, instability and design of pillar workings', International Journal of Rock Mechanics and Mining Sciences, pp. 613-663.

Schofield, A \& Wroth, P 1968, Critical State Soil Mechanics, McGraw-Hill, p. 310, ISBN 978-0641940484.

Valley, B 2012, Structural Geology Guidelines for Burst Prone Mines, Ontario.

Velde, B, Moore, D, Badri, A \& Ledesert, B 1993, 'Fractal and length analysis of fractures during brittle to ductile changes', Journal of Geophysical Research, vol. 98, no. B7, pp. 11935-11940.

Walton, G 2014, Improving continuum models for excavations in rock masses under high stress through an enhanced understanding of post-yield dilatancy, PhD thesis, Queen's University, Kingston, pp. 602. 